\title{
Safety Issues of HG and PB as IFE Target Materials: Radiological Versus Chemical Toxicity
}

S. Reyes, J.F. Latkowski, L.C. Cadwallader, R.W. Moir, J. Gómez del Río, J. Sanz

This article was submitted to

American Nuclear Society $15^{\text {th }}$ Fusion Topical Meeting, Washington, D.C.

November $17-21,2002$

U.S. Dopartmont of Energy

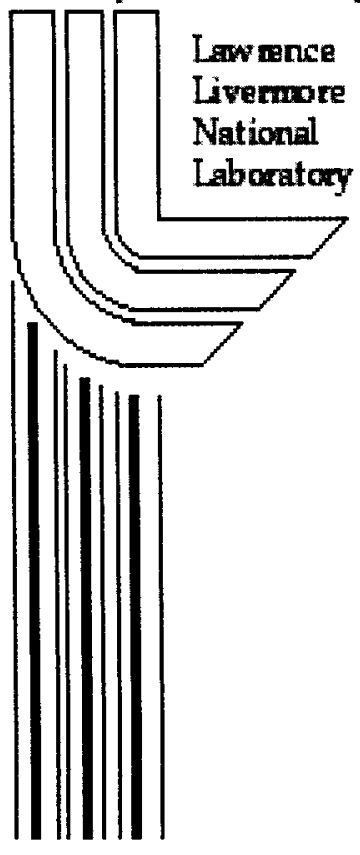

November 11, 2002 


\section{DISCLAIMER}

This document was prepared as an account of work sponsored by an agency of the United States Government. Neither the United States Government nor the University of California nor any of their employees, makes any warranty, express or implied, or assumes any legal liability or responsibility for the accuracy, completeness, or usefulness of any information, apparatus, product, or process disclosed, or represents that its use would not infringe privately owned rights. Reference herein to any specific commercial product, process, or service by trade name, trademark, manufacturer, or otherwise, does not necessarily constitute or imply its endorsement, recommendation, or favoring by the United States Government or the University of California. The views and opinions of authors expressed herein do not necessarily state or reflect those of the United States Government or the University of California, and shall not be used for advertising or product endorsement purposes.

This is a preprint of a paper intended for publication in a journal or proceedings. Since changes may be made before publication, this preprint is made available with the understanding that it will not be cited or reproduced without the permission of the author.

This report has been reproduced directly from the best available copy.

Available electronically at http://www.doc.gov/bridge

Available for a processing fee to U.S. Department of Energy

And its contractors in paper from

U.S. Department of Energy

Office of Scientific and Technical Information

P.O. Box 62

Oak Ridge, TN 37831-0062

Telephone: (865) 576-8401

Facsimile: (865) 576-5728

E-mail: reports@adonis.osti.gov

Available for the sale to the public from

U.S. Department of Commerce

National Technical Information Service

5285 Port Royal Road

Springfield, VA 22161

Telephone: (800) 553-6847

Facsimile: (703) 605-6900

E-mail: orders@ntis.fedworld.gov

Online ordering: http://www.ntis.gov/ordering.htm

OR

Lawrence Livermore National Laboratory

Technical Information Department's Digital Library

http://www.llnl.gov/tid/Library.html 


\title{
SAFETY ISSUES OF HG AND PB AS IFE TARGET MATERIALS: RADIOLOGICAL VERSUS CHEMICAL TOXICITY
}

\author{
S. Reyes ${ }^{1}$, J. F. Latkowski ${ }^{1}$, L. C. Cadwallader ${ }^{2}$, R. W. Moir ${ }^{1}$, J. Gómez del Río ${ }^{3}$, J. Sanz ${ }^{3}$ \\ ${ }^{1}$ Lawrence Livermore National Laboratory, P. O. Box 808, Mailstop L-641, Livermore, CA 94550 \\ ${ }^{2}$ Idaho National Engineering and Environmental Laboratory, \\ P.O. Box 1625, Idaho Falls, ID 83415-3860 \\ ${ }^{3}$ UNED/ ETSII, Dpto. Ingeniería Energética, Madrid, Spain. Instituto Fusión Nuclear, Madrid, Spain
}

\begin{abstract}
We have performed a safety assessment of mercury and lead as possible hohlraum materials for Inertial Fusion Energy (IFE) targets, including for the first time a comparative analysis of the radiological and toxicological consequences of an accidental release. In order to calculate accident doses to the public, we have distinguished between accidents at the target fabrication facility and accidents at other areas of the power plant. Regarding the chemical toxicity assessment, we have used the U.S. DOE regulations to determine the maximum allowable release in order to protect the public from adverse health effects. Opposite to common belief, it has been found that the chemical safety requirements for these materials appear to be more stringent than the concentrations that would result in an acceptable radiological dose.
\end{abstract}

\section{INTRODUCTION}

Indirect-drive targets for future IFE power plants will require a cocktail of high- $Z$ and intermediate- $Z$ materials for production of $x$-rays. The selection of these materials must include many different factors such as cost, extraction methods, compatibility with structures, and safety and environmental (S\&E) issues. Although baseline target designs have used the same cocktail of gold-gadolinium that is used in laboratory experiments $[1,2]$, neither of these is particularly attractive from the cost, or coolant clean-up perspectives, and a wider range of materials should be investigated [3]. The present study focuses on the potential use of $\mathrm{Hg}$ and/or $\mathrm{Pb}$ as high- $\mathrm{Z}$ material in IFE hohlraums, thus, it must be noted that the discussion about potential intermediate- $Z$ materials is out of the scope of this work.

Previous work on IFE target materials has analyzed the radiological characteristics of all stable isotopes in order to identify those that merit further exploration [4].
That work focused on the S\&E of the neutron-activated materials, using three different criteria: contact dose rate, waste disposal rating and accident dose potential. This work showed that both $\mathrm{Hg}$ and $\mathrm{Pb}$ satisfied all three $\mathrm{S \& E}$ criteria. In addition to the radiological results, there are other reasons that support $\mathrm{Hg}$ and $\mathrm{Pb}$ as attractive candidates for IFE target materials. First, either material will be low cost, contrary to the gold traditionally used in laboratory targets. Both materials seem to be appropriate for feasible target production (for $\mathrm{Hg}$, fabrication at temperatures of less than its freezing point of $-39^{\circ} \mathrm{C}$ would be required). Also, a recent study of a flibe coolant cleanup system demonstrated cost-effective methods for $\mathrm{Hg}$ removal by distillation and $\mathrm{Pb}$ extraction via centrifugation [3]. The outcome of that study favored $\mathrm{Hg}$ over $\mathrm{Pb}$ given the simplicity of the distillation process based on the material's volatility.

Even though previous work has been published in the radiological safety area [4], the chemical toxicity issues from the use of either one of these materials in hohlraum fabrication have yet to be addressed. The present work focuses on safety analysis of the use of $\mathrm{Hg}$ and $\mathrm{Pb}$ in IFE targets, comparing the radiological and chemical toxicities for the first time. It should be noticed that the purpose of this paper is to estimate the level of compliance of the safety regulations in case of using two particular materials for target fabrication for IFE, rather than to quantify actual health effects or accident consequences. Therefore, it is assumed that meeting the regulatory standards would prevent any kind of negative health effects to the public in case of an accidental release.

\section{RADIOLOGICAL SAFETY RESULTS}

IFE power plants using indirect-drive targets will need to recycle the target materials due to the large quantities involved-about 1 ton of material per week. In the present 
work, a radioactive cooling time of 1 week is chosen. A study of the effects related to the selection of this cooling time (e.g., resource consumption, impurity levels in coolants, etc.) was performed by Lowenthal et al. [5]. The neutron activation calculations use the neutron spectrum calculated for a reference target design [6]. The spectrum was calculated with the TART Monte Carlo particle transport code [7]. A power plant using this target with a repetition rate of $5 \mathrm{~Hz}$ would consume $-6.6 \times 10^{-2} \mathrm{~m}^{3}$ of high-Z material per week. Neutron activation calculations have been completed with the ACAB98 radionuclide generation/depletion code [8]. Although ACAB allows one to model the pulsed nature (e.g., $5 \mathrm{~Hz}$ ) of the irradiation, calculations have been completed assuming a batch process in which the entire, 1 -week inventory of material is irradiated at once. Thus, simulation of 30 full-power-years of operation required 1560 weekly pulses. In order to bound the worst-case scenario, we assume that the accident occurs at $\mathbf{t}=\mathbf{0}$ after 30 years of irradiation (we do not account for any decay of the material that has been cooling down in the fabrication facility for times up to a week). Once the activities in units of $\mathrm{Bq}$ are known, one can use the specific dose in units of $\mathrm{Sv} / \mathrm{Bq}$ for each isotope, in order to obtain the final accident dose.

The work by Latkowski et al. on the safety analysis for a target fabrication facility [9] showed that both $\mathrm{Hg}$ and $\mathrm{Pb}$ passed the accident dose criteria for the most exposed individual at the site boundary. However, the assumptions on number of canisters, number of targets in each canister, and size of rooms and expansion tanks were arbitrary and need to be optimized. Also, those analyses considered average weather conditions (wind speed $=4 \mathrm{~m} / \mathrm{s}$, atmospheric stability class D) for estimation of early doses, as recommended by the Fusion Safety Standards [10], whereas a new DOE guidance [11] now states that conservative weather conditions (wind speed $=1 \mathrm{~m} / \mathrm{s}$, atmospheric stability class F) are to be used to develop fusion facilities emergency planning. In this work, we have used the most recent guidance to analyze the radiological consequences of an accidental release of activated target material for the two suggested candidates. In order to assess if a protective action is needed, we have used the requirement of "no-public evacuation" criteria of $10 \mathrm{mSv}$ (1 rem) per event, taken from Environmental Protection Agency (EPA) guidance [12].

In order to compare our accident results to the safety criteria, we have calculated the early dose $^{1}$ to the most

\footnotetext{
${ }^{1}$ Early dose is defined as the equivalent effective dose with 50 years commitment, resulting from the first 7 days of exposure during the plume passage. In addition to direct cloudshine and inhalation during plume passage, our doses also consider contributions from groundshine, and inhalation of resuspended material.
}

exposed individual (MEI) at the site boundary $(1 \mathrm{~km})$. Dose conversion factors (DCFs) have been calculated for all radionuclides of interest using the MACCS2 accident consequences code $[13,14]$. Results show that in order to remain below the $10 \mathrm{mSv}$ limit, the mercury mass released must be limited to $4.2 \mathrm{~kg}$. From the target fabrication facility perspective, this is roughly equivalent to $100 \%$ release of a 1-hr supply of targets. Optimization of the number of canisters (assuming failure of each canister does not affect the others) and the expansion tank volume (to reduce the release fraction) would maintain the accident dose well below this limit. As for the coolant loop (which would contain only $0.17 \mathrm{~kg}$ of $\mathrm{Hg}$ assuming a distillation rate of $10000 \mathrm{l} / \mathrm{s}$ [3]) accidental releases would be small enough that the resulting doses form $\mathrm{Hg}$ would be insignificant.

In the case of $\mathrm{Pb}$, a release of $20 \mathrm{~kg}$ would produce a site-boundary dose of $10 \mathrm{mSv}$ under conservative weather conditions. This is equivalent to $100 \%$ release of a $4.5-\mathrm{hrs}$ supply of target material from the fabrication facility. However, the primary coolant loop contains a steady state $\mathrm{Pb}$ inventory of $1700 \mathrm{~kg}$ (assuming centrifugation for the separation technology at a process rate of $11 / \mathrm{s}$ ) [3], and thus, release of the $\mathrm{Pb}$ contained within only $\sim 1 \%$ of the coolant would exceed the $20 \mathrm{~kg}$ value and produce a dose in excess of $10 \mathrm{mSv}$.

It is worth noting that the power plant and the target fabrication plant would be different facilities, so that regulations regarding the safety of hazardous materials would be also different depending on the inventories to be handled in each facility. Whereas $\mathrm{Hg}$ seems to pose a greater hazard for radiological safety in the target fabrication facility, the quantity of $\mathrm{Pb}$ contained within the primary coolant poses a greater risk in the power plant itself. We wish to stress that we are only comparing allowed released fractions for the two materials, without analyzing the mobilization mechanisms that would result in such releases. However, it is expected that under accident conditions the mobilization fraction of $\mathrm{Hg}$ would be much higher than that of $\mathrm{Pb}$ due to its higher volatility (see vapor pressure curves from Figure 1 [15]).

\section{HG AND PB CHEMICAL EXPOSURES}

Both of the potential target materials considered in this work are highly toxic substances. It is known that exposures to mercury or lead cause a variety of effects at low dose levels. A detailed description of these effects can be found in the literature [16-19]. Exposure limits to mercury and lead for the public are given in Table I. Mercury and lead do not have an American Industrial Hygiene Association (AIHA) Emergency Response 
Planning Guideline (ERPG) for public exposure to airborne releases. The U.S. DOE has adopted Temporary Emergency Exposure Limits (TEELs) for hazardous chemicals that do not yet have ERPGs established [20]. The TEELs are chemical concentration values that should protect the public from adverse effects of exposure. TEEL0 is the threshold below which most people will not experience any risk of health effects. TEEL-1 is the maximum airborne concentration below which nearly all individuals could be exposed for up to an hour without experiencing more than mild, transient health effects. TEEL-2 is the maximum airborne concentration below which nearly all individuals could be exposed for up to an hour without experiencing or developing irreversible or other serious health effects, or symptoms that could impair an individual's ability to take protective action. Finally, TEEL-3 is the maximum airborne concentration below which nearly all individuals could be exposed for up to an hour without experiencing or developing life-threatening health effects. It is recommended that, for application of TEELs, the concentration at the receptor point of interest be calculated as the peak 15 -minute time-weighted average concentration [21].

\section{CHEMICAL TOXICITY ASSESSMENT}

Currently, there is no DOE headquarters guidance on public exposure levels to toxic chemicals released at DOE facilities. Several DOE field offices have set up guidelines for limiting public exposures - for example, DOE Order 420.D, from the Idaho Operations Office, provides guidance on public exposure limits for safety analysis [22]. In general, these risk evaluation guideline documents all indicate that one should remain below ERPG-2 or equivalent (i.e., TEEL-2) at the site boundary for extremely unlikely events. Also, work presented in this conference by Cadwallader [23], suggests that exposures of fusion designs need to adopt an upper bound release limit of TEEL-2 for any chemical in the facility as an approach to ensure public safety. Therefore, in this study we have adopted the TEEL-2 as the criteria at which protective actions will be taken.

We have used standard dispersion equations for a continuous release of vapors to the environment to rapidly calculate the quantity of material for the chemicals selected that would be "acceptable" in case of an accidental release. The process to develop quantities of material basically involves back calculating from the standard dispersion equation using the concentration at the point of interest to yield the amount of material released. The standard dispersion equation is long and cumbersome to work with; however, if one is interested only in a ground-level release and in obtaining concentrations along the plume centerline, the standard equation becomes more manageable. Based on Turner's workbook [24], the concentration downwind of a release is given by:

$$
\begin{aligned}
& \mathrm{C}=\mathrm{Q} /(\pi \cdot \sigma \mathrm{y} \cdot \sigma \mathrm{z} \cdot \mathrm{u}) \\
& \text { where } \\
& \mathrm{C}=\text { air borne concentration, } \mathrm{g} / \mathrm{m}^{3} \\
& \mathrm{Q}=\text { rate of release into the air, } \mathrm{g} / \mathrm{s} \\
& \sigma \mathrm{y}, \sigma \mathrm{z}=\text { dispersion deviation, horizontal }(\mathrm{y}), \text { and } \\
& \text { vertical }(\mathrm{z}), \mathrm{m} \\
& \mathrm{u}=\text { wind speed, } \mathrm{m} / \mathrm{s}
\end{aligned}
$$

In working this simplified dispersion equation with a pre-established concentration limit, one can solve for the limiting rate of release into the air. The airborne concentration in the above equation is set as the maximum concentration allowable before protective actions must be taken. We have used Pasquill's set of curves for the various atmospheric stability classes to calculate $\sigma_{\mathrm{y}}$ and $\sigma_{\mathrm{z}}$ [25]. As recommended by the DOE Emergency Management Plan [11], a $1 \mathrm{~km}$ site boundary, F stability class and a windspeed of $1 \mathrm{~m} / \mathrm{s}$ have been assumed.

In the case of $\mathrm{Hg}$, we calculate that a release of 160 $\mathrm{mg} / \mathrm{s}$ would reach the value specified by TEEL-2 $(0.1$ $\left.\mathrm{mg} / \mathrm{m}^{3}\right)$. For $\mathrm{Pb}$, the smaller value of TEEL-2 $\left(0.05 \mathrm{mg} / \mathrm{m}^{3}\right.$ assuming conservatively that it is released as an oxide) would limit the allowed release rate to $80 \mathrm{mg} / \mathrm{s}$. In order to assess the feasibility of such release rates to the atmosphere, we have compared the volatility of each material under the accidental conditions. Mercury is a very volatile metal, which is a liquid at standard temperature and pressure. In the event of a mercury spill at $20^{\circ} \mathrm{C}$, the evaporation rate from the surface of the liquid would be $1.6 \cdot 10^{-8} \mathrm{~g} / \mathrm{s}^{\cdot} \mathrm{cm}^{2}$ [26]. Considering that a release rate of 160 $\mathrm{mg} / \mathrm{s}$ would result in the maximum allowed $\mathrm{Hg}$ concentration in air, it has been estimated that the mercury evaporated from a spill with a radius of $18 \mathrm{~m}$ would exceed the limits for public protection. In the case of lead, an accident at room temperature would not have significant consequences given that the material would be in a solid phase. In order to have a realistic scenario for a liquid spill, we will assume that the accident occurs at $650{ }^{\circ} \mathrm{C}$, which is the actual temperature of the coolant in the HYLIFE-II design. In this case, we have obtained an evaporation rate of $5.4 \cdot 10^{-5} \mathrm{~g} / \mathrm{s}^{\cdot} \mathrm{cm}^{2}$ [27], which means that a relatively small spill $\left(\sim 0.15 \mathrm{~m}^{2}\right)$ of liquid lead would reach the tolerable limits for public protection. It must be noticed that we are not assuming any variation in the temperature of the lead once the accident begins. In a real scenario, it is expected that the liquid released (coolant containing target material) would deposit on colder surfaces, and then the 
evaporation rate would decrease due to the heat transfer from the hot spill to the cooler structures.

Finally, we have performed dispersion calculations in order to give a direct comparison between the radiological and toxicological hazards of $\mathrm{Hg}$ and $\mathrm{Pb}$. Thus, the HOTSPOT code for atmospheric dispersion simulations [28] has been run to analyze the consequences of a direct release of the mass inventories determined in Section II for the radiological safety assessment. We have simulated an instantaneous release of $4.2 \mathrm{~kg}$ of $\mathrm{Hg}$ gas and $20 \mathrm{~kg}$ of $\mathrm{Pb}$ gas ( $1 \mathrm{~m} / \mathrm{s}$ windspeed, F stability class) and have calculated the concentrations at $1 \mathrm{~km}$ from the release point. We have estimated values at the receptor point of interest calculating the peak fifteen-minute time-weighted average concentration, as recommended in Ref. 20. Results show a concentration of $0.3 \mathrm{mg} / \mathrm{m}^{3}$ in the case of $\mathrm{Hg}$ and 1.2 $\mathrm{mg} / \mathrm{m}^{3}$ for the $\mathrm{Pb}$ release. Comparing these results with the TEEL-2 values for public exposure $\left(0.1 \mathrm{mg} / \mathrm{m}^{3}\right.$ for $\mathrm{Hg}$ and $0.05 \mathrm{mg} / \mathrm{m}^{3}$ for $\mathrm{Pb}$ ) one can conclude that the chemical safety criteria are more restrictive than their radioactive safety requirements when assessing public protection from potential gaseous releases of activated mercury and lead.

\section{CONCLUSIONS}

In order to select the high-Z material for IFE targets, one has to account for a series of different factors, including economics, fabrication technologies, compatibility with the rest of materials, extraction, and safety and environmental issues. Lately, several studies have pointed to mercury and lead as potential materials rather than the gold-gadolinium cocktail used in laboratory experiments.

From the S\&E perspective, one should consider two different kinds of hazards when assessing the advantages of one material versus the other: radioactivity of activated materials and chemical toxicity. From the accident analysis perspective, one must distinguish between accidents at the target fabrication facility and accidents in other areas of the power plant. Regarding accidents at the target fabrication facility, $\mathrm{Hg}$ is the most hazardous when estimating radioactive doses to the public. However, segregation of the inventory in the plant and optimization of plant layout should make the $10 \mathrm{mSv}$ limit goal achievable. On the other hand, in case of accidents involving the power plant primary coolant loop, $\mathrm{Pb}$ seems to pose a greater radiological hazard due to its higher inventory suspended in the coolant flow.

Finally, we have performed an assessment of the chemical toxicity of mercury and lead. Results show that from the chemical safety point of view, the concentration limits are similar enough that neither material is an obvious candidate. Release rates of the order of a hundred of $\mathrm{mg} / \mathrm{s}$ would reach the TEEL-2 concentration limit at the site boundary for $\mathrm{Hg}$ and $\mathrm{Pb}$ assuming that they were released in gaseous form. However, the feasibility of such a release must be assessed considering the volatility of the materials. The high volatility of $\mathrm{Hg}$ suggests that it may be a more hazardous option, given its high saturation concentration in air at normal temperatures. Also, we have used the HOTSPOT code to estimate time-averaged peak concentrations that would result if releasing the "allowed" release rates obtained from the radiological safety criterion. A new and interesting finding is that concentrations that would lead to an acceptable radiological dose would exceed the chemical safety requirements. The results from this work demonstrate that whereas radiological hazards dominate the risks of fusion facilities, chemical hazards must also be considered to provide a complete safety assessment for IFE power plants.

\section{ACKNOWLEDGEMENTS}

Work performed under the auspices of the US Department of Energy by University of California Lawrence Livermore National Laboratory under Contract W-7405-Eng-48, Spain Ministerio de Ciencia y Tecnología under Programa Nacional de Fusión Termonuclear Project FTN2001-3886-C02-02, and the European Union keep-intouch Program on IFE.

\section{REFERENCES}

[1] D. A. Callahan-Miller and M. Tabak, "Increasing the Coupling Efficiency in a Heavy Ion Inertial Confinement Fusion Target," Nucl. Fusion 39, 1547 (1999).

[2] D. A. Callahan-Miller and M. Tabak, "Progress in Target Physics and Design for Heavy Ion Fusion," Phys. Plasmas 7, 2083 (2000).

[3] R. W. Moir, "Flibe coolant cleanup and processing in the HYLIFE-II inertial fusion energy power plant," Lawrence Livermore National Laboratory Report, UCRL-ID-143228, 2001.

[4] J. F. Latkowski, J. Sanz, S. Reyes, J. G. Del Rio, "Selection of IFE Target Materials from a Safety and Environmental Perspective," Nuclear Instruments and Methods in Physics Research A, 464, 422-427 (2001).

[5] M. D. Lowenthal et al., Fusion Technology, 34, 619 (1998).

[6] J. G. Woodworth and W. R. Meier, "Target production for inertial fusion energy," Fusion Technology, 31, 280 (1997).

[7] D. E. Cullen, "TART98: a coupled neutron-photon 3D, combinatorial geometry time dependent Monte 
Carlo transport code," Lawrence Livermore National Laboratory Report UCRL-ID-126455, Rev. 2 (1998).

[8] J. Sanz, "ACAB software upgrade," Universidad Nacional de Educacion a Distancia, Lawrence Livermore National Laboratory Report UCRL-CR133040 (1998).

[9] J. F. Latkowski, S. Reyes, G. E. Besenbruch, D. T. Goodin, "Preliminary Safety Assessment for an IFE Target Fabrication Facility," Fusion Technology, 39, 960 (2001).

[10] "Safety of Magnetic Fusion Facilities: Guidance," DOE-STD-6003-96, U. S. Department of Energy, Washington, D. C. (1996).

[11] Emergency Management Guide, volume II, Hazards Surveys and Hazards Assessments, DOE G 151.1-1, US Department of Energy (August 1997) page 3-15.

[12] "Manual of Protective Action Guides and Protective Action for Nuclear Incidents," PB92-164763, U. S. Environmental Protection Agency, Washington, D. C. (1991).

[13]D. Chanin and M. L. Young, "Code Manual for MACCS2, User's Guide," NUREG/CR-6613, Vol. 1, SAND97-0594 (1998).

[14] Gomez del Rio, J; Sanz, J; Reyes, S; Latkowski, JF, "Parametric study of accident consequences from different weather conditions. Application to IFE power plants," Fusion Technology, 39, 1008-1012 (2001).

[15]C. B. Alcock, V. P. Itkin, M. K. Horrigan, Canadian Metallurgical Quarterly, 23, 309 (1984).

[16]Patnaik, A Comprehensive Guide to the Hazardous Properties of Chemical Substances, Second Edition, John Wiley \& Sons, Inc., New York, chapter 37, (1999).

[17] "Toxicological Profile for Mercury," TP-46, Agency for Toxic Substances and Disease Registry, US Public Health Service (1999).

[18] "Mercury Study Report to Congress," EPA-452/R-97003 (1997).

[19] "EPA Heath Effects Notebook for Hazardous Air Pollutants-Draft," EPA-452/D-95-00, PB95-503579 (1994).

[20] D. K. Craig et al., "Alternative Guideline Limits for Chemicals Without Environmental Response Planning Guidelines," American Industrial Hygiene Association Journal, 56, 919-925 (1995).

[22] US Department of Energy, Idaho Operations Office, "Requirements and Guidance for Safety Analysis," Order ID 0 420.D (approved July 17, 2000).

[23] L. C. Cadwallader, "Chemical Hazards and Safety Issues in Fusion Safety Design," presented at the $15^{\text {th }}$ TOFE meeting, Washington D.C, 17-21 Nov 2002.

[24]"Technical Guidance for Hazardous Analysis: Emergency Planning for Extremely Hazardous
Substances," U.S. Environmental Protection Agency, EPA-OSWER-88-0001 (1987).

[25] Meteorology and Atomic Energy, D. H. Slade, Editor, Washington, D. C.: US Atomic Energy Commission (1968).

[26] "Code of Practice Mercury Housekeeping,", Euro Chlor, Environmental Protection 11, $4^{\text {th }}$ Edition (1998).

[27] American Institute of Physics Handbook, Second Edition, McGraw-Hill, 285 (1963).

[28] S. G. Homann, "HOTSPOT Training Manual: Health Physics Codes for the PC," Lawrence Livermore National Laboratory, UCRL-MA-118617 (1995). 
Figure 1. Vapor pressure as a function of temperature for mercury and lead.

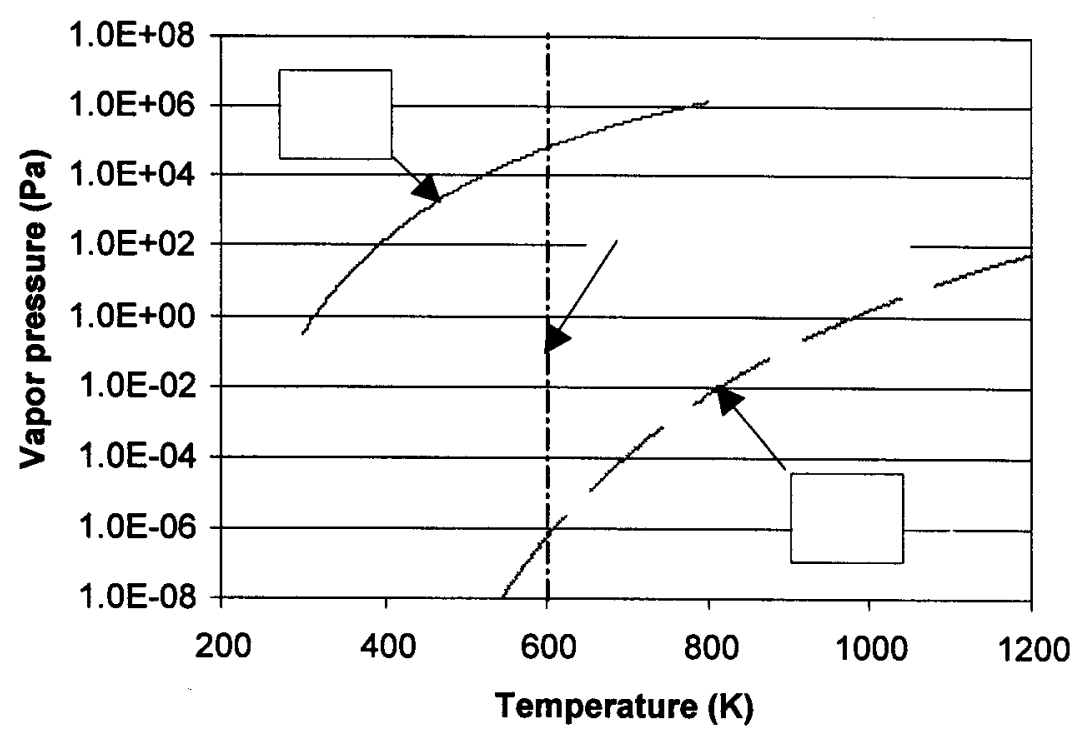


Table I. Public chemical exposure concentration limits for $\mathrm{Hg}$ and $\mathrm{Pb}$ in $\mathrm{mg} / \mathrm{m}^{3}$ in air

\begin{tabular}{|l|c|c|c|c|}
\hline Substance & TEEL-0 & TEEL-1 & TEEL-2 & TEEL-3 \\
\hline $\begin{array}{l}\text { Elemental mercury / } \\
\text { inorganic compounds }\end{array}$ & 0.025 & 0.025 & 0.1 & 10 \\
\hline $\begin{array}{l}\text { Organic } \\
\text { mercury compounds }\end{array}$ & 0.025 & 0.025 & 0.1 & 10 \\
\hline $\begin{array}{l}\text { Elemental lead / } \\
\text { inorganic compounds }\end{array}$ & 0.05 & 0.15 & 0.25 & 100 \\
\hline Lead dioxide & 0.05 & 0.15 & 0.25 & 100 \\
\hline Lead oxide & 0.05 & 0.05 & 0.05 & 100 \\
\hline
\end{tabular}

